\title{
ALFONSO REYES EN PARÍS A TRAVÉS DE SU CORRESPONDENCIA CON GENARO ESTRADA
}

El 4 de octubre de 1924 Alfonso Reyes se embarca en Nueva York en el Veedam rumbo nuevamente a Europa después de una estancia de varios meses en México. Su paso por Monterrey fue especialmente conmovedor para él — como se lo confiesa a Genaro Estrada - al verse asaltado por las muchachas que lo "raptaban en su auto"1. En Madrid permanece poco tiempo y ya a principios del mes de noviembre se encuentra en París esperando un nuevo nombramiento diplomático. Un mes más tarde su amigo Rafael Cabrera, quien todavía trabajaba en la Legación de México en París, le enseña un telegrama con la noticia de que Reyes acababa de ser nombrado Ministro en la capital francesa. Este inesperado honor lo llena de una alegría desbordante que comparte en seguida con su "Gordo único, Buda de la Amistad" y reconoce que está "como en sueños". Así empieza una nueva etapa en la brillante carrera de Reyes como representante de su país.

A través de las cartas que se han conservado entre Reyes y Estrada $^{2}$, quien era Subsecretario de Relaciones Exteriores, se puede seguir de cerca el desarrollo de esta nueva época. Es interesante notar que, pese a los años transcurridos en el extranjero (desde 1913), el amor que Reyes siente por su patria no ha disminuido. Al contrario, se da cuenta de que sólo en su tierra vive plenamente. Le dice a Estrada en carta del 13 de diciembre de 1924: "Yo sé que en todas partes sólo vivo provisionalmente, y que los meses periódicos (conste que no he dicho los periodos men-

${ }^{1}$ Carta de Alfonso Reyes a Genaro Estrada con fecha del 3 de octubre de 1924, escrita en Nueva York.

${ }^{2}$ Damos las más expresivas gracias a Alicia Reyes, directora de la Capilla Alfonsina, por habernos proporcionado este material con el fin de preparar una edición crítica de toda la correspondencia Reyes-Estrada. 
suales) de estancia en México, serán los verdaderos hitos, las estaciones centrales del ferrocarril de mi vida (si Ud. me permite... )". Por eso le duelen las declaraciones de sus paisanos - los jóvenes- que lo acusan de ser un escritor español aunque sabe que el tiempo le hará justicia ${ }^{3}$. Reyes se siente profundamente mexicano y aprovecha su situación diplomática para transmitir este orgullo. Apenas instalado en París ya hace planes para que se publique allí lo mejor de la literatura mexicana y para que se funde una Casa de México con el fin de dar a conocer el espíritu nacional, empezando con una exposición y una biblioteca bien escogida. Reyes sabe que no solamente "la opinión de París hace, en asuntos espirituales, la opinión del mundo"' , sino que los juicios de los demás nos ayudan a conocernos mejor. También se interesa por estimular y reconocer la obra de artistas como Carlos Bracho y Ángel Zárraga. A Reyes le parece imprescindible que el Estado apoye la cultura mexicana, la cual ha alcanzado un envidiable nivel. Por otra parte, desde los primeros días en París, lucha incansablemente porque México tenga un edificio que sea más digno del país que representa. En sus frecuentes cartas a Estrada - las cuales parecen ser "de cocinera, de ama de casa" según el propio Reyes-, no deja de lamentarse de las condiciones pésimas que plagan la Legación debido a la falta de un presupuesto adecuado. Le mortifica ver que ésta es la peor de todas las latinoamericanas. Lo cierto es que Reyes toma muy en serio sus nuevas responsabilidades y anhela por encima de todo mejorar la imagen de México en el extranjero. Aunque no puede dedicarse a sus trabajos literarios sino hasta las altas horas de la noche, está convencido de que su labor diplomática es sumamente útil y de ahí deriva una inmensa satisfacción. Con toda su energía e inteligencia se entrega al servicio de México, pero se le hace difícil aceptar las críticas que a veces le dirigen los periódicos y los políticos. Las envidias y las intrigas que lo persiguen le causan mucha amargura y aun algunas dudas. En Estrada, sin embargo, encuentra alivio a sus inquietudes y le confiesa su preferencia por una vida más sosegada: "yo estimo en más la serenidad, la placidez, la buena intención" (22 de octubre de 1925).

Con todo, esta nueva etapa parisiense es de felicidad para Re-

${ }^{3}$ Reyes le dice a Estrada el 9 de diciembre de 1924: “'Si serán pendejos! Esto no es, en el fondo, más que ganas de que yo no entre en la cuenta. Pero al tiempo me fío, como en todo lo que hago. Ello dirá, y si no, lo diré yo".

${ }^{4}$ Carta a Estrada fechada el 8 de febrero de 1925. 
yes, quien vuelve a gozar de los encantos de la ciudad-luz y especialmente de la visita de compatriotas suyos como Enrique González Martínez, Agustín Loera y Chávez, Vicente Lombardo Toledano, Félix Palavicini, Carlos Pellicer y su querido Xavier Icaza, "con su buen humor de siempre, su bondad, su simpatía". Espera la llegada de José Vasconcelos y sueña con la presencia de su "hermano el diablo", Julio Torri, a quien le reserva sus confidencias más íntimas y líricas. Las noticias que siempre anhela tener Reyes de México ${ }^{5}$, no obstante, no las encuentra en las cartas de Torri sino en las de Estrada. Así se va enterando de la situación de sus amigos Francisco A. de Icaza, Luis G. Urbina, José Vasconcelos e inclusive la de sus familiares. Además Estrada le anuncia la llegada de Ana Pavlova a México, le pide obras de James Joyce y ciertas publicaciones francesas, le informa que por falta de tiempo no seguirá encargado del Pen Club y le explica que por razones políticas ha dejado de colaborar por algún tiempo en El Universal, lo cual le ha provocado algunos problemas: "No tengo donde escribir y necesito escribir. Las revistas de aquí son muy malas, sin contar con que casi siempre hay en ellas gente de mucho jijismo". Reyes queda impresionado por la vasta labor emprendida por Estrada en las nuevas series de Monografías Bibliográficas de México y del Archivo Diplomático Mexicano, en las cuales le promete colaborar. Todo lo que Estrada le cuenta de sus proyectos, sus compañeros (Castro Leal, Cosío Villegas, etc.) y sus viajes le encanta: "sus cartas son para mí el rocío del cielo". Pero también lee con agrado sus artículos periodísticos y lo anima a publicar más. Tales sugerencias no tardan en verse realizadas en el infatigable Estrada, quien para octubre de 1925 le escribe a Reyes que ha terminado un libro ("Es cosa mexicana') ${ }^{6}$ y ha hecho un ballet, con música de Carlos Chávez y decorado de Diego Rivera, que se titula The white prince. También se propone hacer un "libro literario" ilustrado por Miguel Covarrubias durante sus próximas vacaciones en los Estados Unidos (noviembre y diciembre de 1925) y reanudar sus colaboraciones periodísticas.

Por su parte, en este año de 1925, Reyes lo tiene al tanto de su deseo de escribir artículos en francés para la Nouvelle Revue Fran-

${ }^{5}$ Dice al respecto en carta a Estrada del 8 de febrero de 1925: "Las noticias de México son el alimento de mi alma".

${ }^{6}$ Se trata de su novela Pero Galín, que al principio quería publicar en España con Rafael Calleja. Aparecerá en 1926 en la Editorial Cultvra de México. 
çaise y de la posibilidad de que Gallimard edite la traducción que preparó Jean Cassou de El plano oblicuo. Y saldrán otros libros suyos ahora que por fin han llegado sus manuscritos de México, lo cual lo ha llenado de alegría. El 2 de junio le confía a su amigo que éstos "han tenido conmigo un encuentro amoroso verdaderamente conmovedor. Casi me he tenido que meter en la cama después'. Aunque se ve agobiado de compromisos sociales, hace lo imposible para continuar con su trabajo literario. No quiere ser como su compañero ecuatoriano Gonzalo Zaldumbide, quien aparentemente había dejado de escribir debido a sus obligaciones como Ministro de su país en París. Sin cesar Reyes pide a Estrada más personal para que pueda dar brillo a su Legación. Recomienda como posibles colaboradores a Agustín Loera y Chávez y sobre todo a Antonio Castro Leal quien, sin embargo, prefiere instalarse en Washington luego de una estancia de cuatro años en Santiago de Chile.

Los problemas de la Legación siguen preocupando a Reyes en 1926 y sobre todo surge una situación que le causará mucho sufrimiento. Con fecha del 26 de enero Estrada le manda copia de una carta confidencial dirigida a Enrique González Martínez, Ministro de México en Madrid, en la cual le comunica los reparos que tiene el Presidente Plutarco Elías Calles (según Aarón Sáenz) respecto a la labor diplomática de ambos escritores. Sobre todo se les reprocha dedicar demasiado tiempo a la literatura en vez de ocuparse de sus responsabilidades oficiales. En conversación con Aarón Sáenz, Ministro de Relaciones Exteriores, Estrada defendió a sus amigos explicándole que es precisamente debido a su prestigio literario que ambos han conseguido tales puestos. $\mathrm{Y}$ sigue aclarando que

la literatura es, en el caso de ustedes, no solamente un poderoso auxiliar para su labor oficial sino uno de los mejores auxiliares con que cuentan pues que, destacándose por medio de ella, logran atraer la atención hacia México y logran relaciones muy importantes que, como tales, son también benéficas para el país.

Además, subraya que los dos han sabido destacarse en otros asuntos aparte de los literarios. Sáenz acepta esas apreciaciones, pero no queda del todo satisfecho y señala como modelo la labor de otros ministros. Para que Estrada pueda defenderlos aún más, les sugiere que hagan resaltar sus actividades. Lo esencial es que se sepa en México lo que están realizando en el extranjero. Así esta- 
rán a salvo de toda crítica o peligro que pueda haber en el futuro. El 23 de febrero Reyes le envía a Estrada una larguísima carta "muy confidencial" en la cual responde a las acusaciones que le han hecho esperando que sus palabras lleguen al Ministro de Relaciones Exteriores y al Presidente de la República. Explica que ha cumplido con su deber "sin cacarearlo después ni importarme gran cosa que los demás lo sepan". Por carecer de ambición política y por modestia Reyes no juzgó necesario llamar la atención sobre las innumerables actividades y tareas que le han correspondido. En esta ocasión no se referirá a la importancia que tiene el trabajo intelectual para un diplomático, sobre todo radicado en París, donde es preciso ser "un soldado de la cultura". En cambio, apunta que su misión como ministro ha sufrido algo por tener que ocuparse de todos los aspectos burocráticos de la Legación, incluyendo la contabilidad, la reorganización del archivo, la preparación de expedientes, la redacción de notas y mil cosas más, "hasta de criado de la Legación". Con todo, insiste sobre las buenas relaciones que ha sabido establecer con el gobierno francés y la sociedad parisiense, lo cual no es nada fácil ("París no es cosa de juego"). Sin embargo, reconoce que podría haber logrado mucho más, si lo hubieran apoyado en los proyectos que había propuesto. En París no se puede hacer cualquier cosa y para tener éxito se requieren fuertes recursos. Reyes hace hincapié en el hecho de que trabajar en la capital francesa no es lo mismo que desempeñar el mismo puesto en otro país. Con suma sensibilidad entiende las maneras de ser y las particularidades que caracterizan a la nación donde se encuentra. También se da cuenta de que por envidia lo han criticado algunos, ya que París es uno de los puestos más solicitados. Considera que a menudo sus acciones han demostrado su lealtad política y que por lo tanto las críticas que ha recibido han sido totalmente injustas. Se siente herido por la falta de reconocimiento de todo lo que ha conseguido en tan poco tiempo y sobre lo cual ha querido insistir. En particular reitera que ha dedicado todos sus esfuerzos al ejercicio de la diplomacia: "Nunca, por ningún motivo, he descuidado el menor de mis deberes oficiales, ni mucho menos lo he postergado a mis actividades literarias". Termina diciendo que, de acuerdo con los deseos de sus susperiores, "hará ruido" y tratará de servir de la mejor manera posible a su país.

El mismo día Reyes le escribe dos cartas más sobre el mismo asunto. En la primera "carta para Ud. solo" agrega lo que no quiso decir en la anterior: "no me atreví a decir claro que hasta 
hoy no me he sentido lo bastante apoyado políticamente". Sabe que no pocos lo consideran reaccionario y tiene la impresión de que el Presidente no lo estima. Por eso ha preferido quedar tranquilo y no llamar la atención. Se queja de que lo tratan como a un "muchacho menor de edad" y que no lo tienen informado sobre la situación política de México. Ha sido tanto su dolor - le confiesa a Estrada - que estuvo a punto de renunciar y todavía lo haría a la menor indicación de sus jefes. Por otra parte, le causa angustia el rumor de que pronto Alberto J. Pani regresará a París como ministro. Reyes pasa por unos momentos de profunda amargura e incertidumbre cuando sólo depende del "gran corazón de amigo" de Estrada. El mismo 23 de febrero Reyes le manda unos renglones escritos a mano ("Sólo para usted") acerca de otras actividades que pudo organizar, aunque poco le agrada tener que jactarse. De aquí en adelante se lo dirá todo para que se den cuenta de su incansable labor a favor de México. $\mathrm{Al}$ día siguiente -el 24 de febrero- vuelve a dirigirle a Estrada una carta más ("Sólo para usted") para expresar su atormentado estado de ánimo: "No duermo ya. Pienso que tal vez debí renunciar lisa y llanamente [... ]. Sufro mucho". Aunque no necesita convencer a su amigo, Reyes le recuerda que en París admiran a un país que tiene como su representante a un poeta (se lo dijo St. John Perse). Está agobiado de trabajo y le mortifica que no reconozcan oficialmente todo lo que ha hecho por su patria. El 26 de febrero Reyes le comunica otro testimonio, esta vez de $\mathrm{Ga}$ briela Mistral, quien tuvo la impresión de que Reyes era "el americano más popular" de París. Le da vergüenza tener que hablar de sí mismo constantemente, pero a eso lo han obligado. El mismo día le vuelve a escribir a Estrada, acerca de asuntos administrativos, y sobre todo propone como escribiente auxiliar al Abate Mendoza, de quien tiene muy buena impresión. En particular aprecia sus conocimientos filosóficos y literarios y agrega: "es muy superior a todo el cuadro actual de la Legación, en todos los órdenes". Pero aclara que no lo quiere por ser literato sino porque es una persona muy bien preparada cuya ayuda será inestimable para la Legación. El excesivo trabajo burocrático y "aquel asunto" no dejan de producir en Reyes un hondo sentimiento de tristeza y amargura.

Como consecuencia de aquella situación desagradable, las cartas que siguen llevan una gran cantidad de información relativa a las agobiantes tareas oficinescas y oficiales en esa Legación "carcomida de vicios". Más que nunca Reyes se esfuerza, con la or- 
ganización de actos de propaganda, en satisfacer los deseos de la Secretaría. El 28 de febrero es interesante notar que, al enterarse Reyes de que Xavier Villaurrutia piensa pasar algún tiempo en Europa, lo propone como colaborador suyo en el despacho: "No hay que consentir que se malogre la mejor promesa de nuestra juventud literaria".

Como prueba de que la dedicación de Reyes al trabajo diplomático es entera, no solamente se niega a colaborar en periódicos como El Universal o Excélsior, sino que subraya el hecho de que los únicos libros que publicará durante 1926 reúnen material elaborado en otra época, a saber Reloj de sol y Pausa. En París sólo ha podido escribir unos cuantos discursos que considera como parte de su responsabilidad pública. Además, no le ha sido posible preparar un cuento adicional para la versión francesa de El plano oblicuo que iba a publicar Gallimard. Esto le angustia profundamente, porque tal libro lo incorporaría a las letras francesas y contribuiría de manera significativa a su prestigio literario. Con amargura dice: "Esto es lo mucho que me distraigo con la literatura" (8 de marzo de 1926). Aun se ha visto obligado a rehusar las mejores condiciones posibles en cuanto a colaboraciones literarias para poder protegerse de toda acusación.

Al regresar de un viaje oficial de Lyon, Reyes vuelve a comentar aquel "asunto tan enojoso" en una carta que le dirige a Estrada el 12 de marzo, subrayando nuevamente la significación de su trabajo en París. Como muestra del prestigio que le han concedido los intelectuales franceses, le envía una carta de Raymond Foulché-Delbosc y recuerda la excepcional acogida que le brindaron a su llegada Valery Larbaud y Francis de Miomandre, así como el banquete ofrecido un poco después por las colonias americanas con discursos de Ernest Martinenche, Jean Richepin y Gonzalo Zaldumbide, entre otros. Deben tomarse en cuenta tales triunfos; agrega: "Yo francamente me figuro que estas cosas son compatibles en mi haber y - digamos- no muy frecuentes". Tampoco hay que olvidar - sigue Reyes- sus conferencias en la Sorbona y en otras partes, sus entrevistas, su lectura de Ifigenia cruel, la cual "no empaña precisamente el buen nombre de la representación mexicana". No cabe duda de que le causa mucho dolor tener que defenderse de esa manera y confiesa con conmovedora sinceridad:

Me han sometido a una verdadera tortura. Yo nunca he hecho esto, pero no quiero perder sin justicia, por eso me defiendo. $\mathrm{Me}$ 
duele, me duele tener que hacer valer lo que Uds. creo yo han apreciado bien. Si Uds. tienen los datos, y de veras creen en mí y me tienen confianza, no me obliguen a que yo haga esto. Uds. saben a qué atenerse. ¡Estoy más dolido, más triste!

El 20 de abril de 1926 Genaro Estrada le escribe a Reyes sobre aquel "caso molesto" expresando su pena por lo que han tenido que hacer (Estrada y Enrique González Martínez) para aclarar su situación, aunque él estaba muy consciente del valor de su trabajo. Aquellas explicaciones le han sido muy útiles en sus encuentros con el Ministro de Relaciones Exteriores, a quien considera como un hombre comprensivo y bueno. Después de examinar ampliamente el caso, Aarón Sáenz quedó satisfecho, igual que el Presidente Calles. Así se resolvió este asunto de intrigas políticas que tanto influyó en Reyes.

Con la siguiente carta de Estrada $\left(1^{\circ}\right.$ de mayo) se reanuda el diálogo habitual, es decir el intercambio de datos, noticias, etc. Entre éstas, por ejemplo, la presencia de un artículo de Gabriela Mistral en El Universal, la publicación de otras Monografías Bibliográficas, la necesidad de reimprimir Huellas, el deseo de Rufino Tamayo de marcharse (en su exposición sólo Estrada le compró un cuadro), la colaboración de los escritores Joaquín Ramírez Cabañas y Francisco González Guerrero en la Secretaría y la próxima aparición de su novela Pero Galín, cuya edición cuida meticulosamente:

Mi librillo está impreso hace un mes; pero no he querido que salga a la diabla, con esa horrorosa presentación que por ahí se usa. He hecho que se empaste toda la edición con los detalles de los buenos libros que ahora se hacen en los Estados Unidos. Creo que la semana entrante habrá ejemplares.

También le sugiere a Reyes que los dos funden una buena revista seria "para justificar la calidad literaria de México". Propone que se haga en París, porque eso le daría importançia y buena difusión. Todo vuelve a la normalidad luego de la crisis que había dominado este intercambio epistolar y ahora los dos amigos discuten de nuevo los temas que les interesan. De paso cabe notar que Reyes comenta poco o nada aquel problema en su correspondencia con otros amigos o en su Diario. A Pedro Henríquez Ureña, en carta del 19 de abril de 1926, ya pasados los momentos más desalentadores, tan sólo le dice: "Exceso de trabajo. Intrigas 
políticas a las que hubo que responder con la mejor defensa del hombre honrado: redoblando mis actividades y esfuerzos. Parece que pasó la nube"'7. Unas semanas más tarde Reyes vuelve a referirse a esa situación, afirmando que ha salido victorioso: "Aún no caigo. Lo único que puede hacerme rodar es la intriga: tuve, en efecto, molestias, intrigas, de ambiciosos del puesto: las vencí del todo: salí más fuerte que antes"'8. En cuanto a su Diario sólo se menciona ese asunto el 16 de mayo de 1926, cuando Reyes se queja de la necesidad de dejar constancia de todas sus actividades y critica en general la vida política. Confiesa: "Apenas empiezo ahora a aprender a exhibir lo que hago, a demostrarlo. Eso es la política, y por eso abomino de ella"'9.

A raíz de la publicación de la primera novela de Estrada, Reyes le manda el $1^{\circ}$ de junio el siguiente telegrama: "Pero Galín, delicia perfecta" y unos días más tarde (el 11 de junio) comenta: "El Pero Galín me transporta a un mundo mejor: al mundo en que México produzca ya sólo libros perfectos. Ya le escribiré despacio sobre esto" 10 . Asimismo expresa su admiración por las valiosas Monografías Bibliográficas que continúa publicando Estrada y lamenta no poder colaborar en ese proyecto. Pero por lo menos le agrada la aparición de su Reloj de sol, último tomo de Simpatías y diferencias. Como se lo había prometido, Reyes vuelve a Pero Galín en una carta fechada el $1^{\circ}$ de julio de 1926 , la cual viene a ser como una nota crítica sobre dicho libro. Debido a su interés se reproduce íntegramente:

\section{Querido Genaro:}

El Pero Galín (ya he visto que ha tenido muy buena crítica) es un libro de 20 atmósferas. Una rara concentración de ambiente mexicano, compacto, fuerte, apretado: abre uno la boca, y México se le entra como un ventarrón. No hay espacio perdido, no hay com-

${ }^{7}$ En Pedro Henríquez Ureña y Alfonso Reyes, Epistolatio intimo (19061946), recopilación de Juan Jacobo de Lara, Universidad Nacional Pedro Henríquez Ureña, Santo Domingo, 1983, t. 3, p. 317.

${ }^{8}$ Carta del 10 de junio de 1926 , ibid., p. 321.

${ }^{9}$ Alfonso Reyes, Diario 1911-1930, pról. de Alicia Reyes y nota del Dr. Alfonso Reyes Mota, Universidad de Guanajuato, Guanajuato, 1969, p. 132.

${ }^{10}$ En carta a Valery Larbaud con fecha del 4 de junio de 1926 Reyes dice: "He aquí un buen libro mexicano. Su autor, el Subsecretario de Relaciones Exteriores, es el hombre de mejor equilibrio en México", en VALERY LARBAUd-Alfonso Reyes, Correspondance 1923-1952, avant-propos de Marcel Bataillon, introd. et notes de Paulette Patout, Didier, Paris, 1972, p. 42. 
pás muerto. Ud. que ha tenido siempre algo como el instinto de la madurez, ha dado aquí una obra plena. Y de inmensa curiosidad: hormigueante de cosas que pican los ojos y tientan las manos, como una biblioteca nutrida o un escaparate lleno de primores. Estoy realmente encantado, y fui de una sinceridad matemática cuando le telegrafié: "Pero Galín, delicia perfecta'. De la edición también podría decirle muchas cosas. Ha hecho, ha obtenido Ud. una maravilla. Se adivina al instante que el hombre que publica ese libro tiene algo de obrero de libros, entiende el metier. Su libro puede ir a una exposición, y yo me propongo mostrarlo en alguna ocasión pública a título de muestra de primera. Yo creo que, en cuanto al estilo, puede Ud. ya descansar tranquilo: que lo sacuda el aire de la vida a su antojo: el árbol ya está fuerte. Un abrazo muy largo.

Alfonso

En París, como se sabe gracias a Paulette Patout ${ }^{11}$, Reyes cuenta entre sus amigos a los intelectuales y artistas franceses de mayor relevancia. En particular tuvo una buena amistad con el compositor Darius Milhaud, tema de una carta que le manda a Estrada el 5 de julio de 1926. De hecho, como consecuencia de sus conversaciones con Reyes, el músico francés se interesa por conocer a México y especialmente su "vitalidad musical". Según Reyes tal viaje sería beneficioso tanto para Milhaud como para sus colegas mexicanos. Inclusive podría - piensa Reyes- componer una Sinfonía Mexicana que contribuiría a la imagen de México "como tierra de nobles inspiraciones y vasta riqueza de espíritu y sensibilidad". Insiste con Estrada para que la Secretaría de Relaciones Exteriores le extienda una invitación a Milhaud, pero por razones desconocidas no se efectuó esa visita que tanto había deseado Reyes.

Las quejas de Reyes relativas a la insuficiencia de fondos y la escasez de personal en la Legación vuelven a aparecer en sus cartas, pero son de corta duración, ya que el 20 de septiembre asevera: "Mi Legación ha llegado a un equilibrio [...]. Al fin llegamos al equilibrio". Por primera vez Reyes se siente optimista, contento y satisfecho con la ayuda de su personal, lo cual le permitirá dedicarse totalmente a la "verdadera propaganda". Le causa mucha alegría el haber preparado el Tratado de Comercio y Amistad entre México y Francia y espera que le reconozcan tal

11 Paulette Patout, Alfonso Reyes et la France, Service de reproduction de thèses, Lille, 1981. 
logro. Con suma energía concibe toda clase de programas y trabajos para ensalzar el perfil de México. Este nuevo entusiasmo, sin embargo, es abruptamente sofocado con la noticia de un cambio inesperado. Agrega a la carta anterior: "¿Qué ironías de la vida! Ayer le escribía yo a Ud. esto, y hoy, día 21 recibo su mensaje anunciándome mi próximo probable traslado, por viaje de Pani; sea por Dios!' En su Diario Reyes alude a ese cable y expresa la pena que le produce tener que abandonar París ahora que todo anda bien (y también por la educación de su hijo) y volver a enfrentarse a un futuro incierto. Prefiere no preguntarle nada a Estrada, pero cree que quizás lo mandarán a Río de Janeiro o a Madrid ${ }^{12}$. De hecho, otro telegrama de Estrada le anuncia su posible traslado a España, lo cual haría "de buena gana"13. De ser así Enrique González Martínez pasaría de Madrid a la nueva Legación en Suiza, propuesta que rechaza en seguida el célebre poeta. Ante tal situación le entran a Reyes sentimientos contradictorios de felicidad al pensar en Madrid y de tristeza al tener que dejar París, y sobre todo le preocupa el dilema de su querido amigo, a quien intenta convencer de la conveniencia de ir a Suiza. No obstante, en carta del 29 de septiembre, le asegura que puede permanecer en Madrid si ése es su deseo. Para nada quiere Reyes causarle inquietudes o molestias y le reitera su hondo afecto: "Estamos unidos más allá de los puestos de Relaciones y ambos dispuestos a lanzar todo por la borda, así es que..." 14 . El mismo día Reyes le comunica a Éstrada su afán de servir de la mejor manera posible a México mediante el ejercicio de la alta diplomacia. Por motivos de amistad desiste de regresar a España y está dispuesto a trasladarse a Suiza. Lo cierto es que permanecerá todavía unos meses en París antes de volver a América.

Luego de ese periodo lleno de crisis, Reyes ofrece a Estrada el 2 de octubre un interesante examen de sí mismo a raíz de unas notas que había redactado sobre su vida pública en momentos de desesperación. Admite que sus frustraciones siempre desembocan en alguna meditación intelectual y no en una lucha más emotiva, es decir que suele triunfar el espíritu sobre la materia. Como escritor piensa que tiene la obligación de escribir acerca de una parte tan importante de su vida como lo es su actividad política. Nada fácil es la situación del diplomático quien, alejado de su país, no

12 Diario, pp. 149-151.

13 Ibid., p. 152.

${ }^{14}$ Carta reproducida en Ábs, 18 (1954), 94-95. 
puede responder a tiempo a las críticas de la prensa ni puede expresarse con toda libertad debido a su oficio. Lo importante es asimilar todas esas experiencias: "Después de todo, es mucho mejor entender que pelear, y es la estrategia más segura de la victoria". Con serenidad Reyes reconoce que los reproches de que ha sido objeto lo han ayudado a examinarse y a estimar a sus colegas menos afortunados que él. Pero sobre todo está convencido de que esa experiencia debería ser la base de un libro y sólo espera encontrar el tiempo para escribir sus "confesiones de un hijo del siglo". El sólo pensar en ese proyecto lo estimula, y llega a las siguientes observaciones acerca de la labor intelectual:

Gano buen sueño en cuanto pienso y escribo; se corrige mi economía vital, siento que una energía pacífica entra en mí e invade mi ser como agua buena - más eficaz que todos los tónicos, todos los ejercicios al aire libre y demás materialidades que aconseja nuestra medicina. Es el aire libre del espíritu que obra sus milagros en mí: es Dios.

Sus escritos, no obstante, suscitan comentarios a veces desfavorables en la prensa mexicana, lo cual lo mortifica. El 25 de octubre, en cartas a Pedro Henríquez Ureña y a Génaro Estrada se queja de esa "incomprensión" e "inexperiencia literaria" que todavía reina en México en contraste con lo que sucede en París o en Madrid. En particular le resulta incomprensible que nadie lo defienda de las acusaciones hechas a raíz de la "Carta a dos amigos", texto que se incluye al final de Reloj de sol y que va dirigido a Genaro Estrada y Enrique Díez-Canedo ${ }^{15}$. Esas críticas y la escasez de correspondencia procedente de México lo desaniman, como se puede ver cuando le dice a su único amigo: “¡Da tanta pena sentirse tan solo, tan abandonado ya por haber cometido el crimen de tener amor al trabajo! ¡Vamos: una palabra de alivio, Genaro! ¡Ud. que es bueno!’ (25 de octubre de 1926).

Tras un prolongado silencio, por fin Estrada le da algunas noticias a Reyes el 17 de noviembre de 1926. Le informa de la enfermedad de José Juan Tablada en Nueva York (Estrada escribe sus crónicas en El Universal para que su amigo no pierda su suel-

${ }^{15}$ A su amigo cubano José María Chacón y Calvo, Reyes le dice el 30 de octubre de 1926: "En México han tomado el rábano por las hojas. ¡Y me atacan por la explosión de vanidad de mi "Carta a dos amigos» (!!!) y por la falta de interés crítico (!) de mis páginas de simples recuerdos (!!!!!). Me llegó la hora de ostracismo", en ZenaIDA GuTiÉrRez-VEGA, Epistolario Alfonso ReyesJosé Ma. Chacón, Fundación Universitaria Española, Madrid, 1976, p. 127. 
do) y de la ayuda que le proporcionó a Luis G. Urbina. Desde la Secretaría de Relaciones Exteriores el bondadoso Estrada no se olvida de sus amigos escritores y trata de aliviar sus problemas económicos mediante el otorgamiento de subsidios o comisiones. Como siempre sigue muy activo en innumerables proyectos bibliográficos, históricos y literarios, algunos de los cuales verán la luz y otros no.

Con una bella carta de Reyes fechada el 28 de diciembre se cierra el año de 1926 así como, salvo por dos o tres recados más, esta segunda etapa parisiense en la vida del humanista mexicano. Esta misiva enviada a su "gordo tierno y dulce" es esencialmente una sincera expresión de la amistad que los une. Reyes reconoce que durante este año que ha resultado difícil para él, el comportamiento de Estrada ha sido inmejorable: "Pero Ud., Amigo con A mayúscula! ¡qué generoso! ¡qué bueno! ¡qué igual!’ Satisfecho con todo lo que pudo hacer en París pero triste ante la idea de marcharse de nuevo, Reyes ya prepara su inminente traslado a la Argentina. Igual que dos años atrás, los intelectuales franceses expresan su admiración y afecto con un concurrido banquete y, además, Reyes recibe la Encomienda de la Legión de Honor. El 16 de marzo le entrega la Legación a su sucesor, Alberto J. Pani. Al día siguiente de una recepción ofrecida por Reyes a mil personas, se dirige con su familia al puerto de St. Nazaire y de allí salen rumbo a América el 20 de marzo de 1927. Las palabras finales de una carta de despedida escrita unos días antes por Reyes a su querido compañero Valery Larbaud revelan con sencillez los sentimientos del futuro Embajador de México en Buenos Aires: "Adiós, pues, o hasta luego. A ver si mi suerte me consiente volver un día entre Uds. Aquí dejo tantos afectos, tantos intereses intelectuales, tantos recuerdos gratos. No puedo ocultarle que estoy triste" 16 . Con el tiempo - como se lo confiesa a Pedro Henríquez Ureña- Reyes echa raíces cada vez más profundas y le duele tener que volver a quemar las naves. Si bien la diplomacia tiene sus innegables atractivos, la inestabilidad inherente a esa profesión empieza a afectar a Reyes, quien le confía a su amigo dominicano lo siguiente: "No cabe duda que la vida diplomática es escuela de santidad. Para mí, en todo caso, disciplina de sufrimiento"17. La correspondencia de Alfonso Reyes

${ }^{16}$ Carta fechada el 10 de marzo de 1927, en Correspondance, p. 47. p. 328 .

${ }^{17}$ Carta fechada el 19 de diciembre de 1926, en Epistolario intimo, t. 3, 
con Genaro Estrada ofrece un valioso testimonio de este periodo durante el cual Reyes trata de reconciliar con grandes dificultades las exigencias de la diplomacia con su vocación de escritor, pugna que no se resolvería hasta su regreso definitivo a México en 1939.

Serge I. ZaïtzefF University of Calgary 